\section{Phosphogluconate Dehydrogenase Polymorphism in British Wild Rats}

Phosphogluconate dehydrogenase (PGD) has been found to be polymorphic in several species, including the rat, when studied by starch gel electrophoresis ${ }^{x}$. Investigation of this cnzyme in the rat revealed three distinct electrophoretic phenotypes, giving respectively a slow migrating component, the $\mathrm{S}$ phenotype, a fast migrating component, the $\mathrm{F}$ type, and the $\mathrm{SF}$ phenotype, giving a triplet of electrophoretic bands comprising both the slow and the fast migrating bands, and also a strongly staining band with intermediate mobility ${ }^{2}$. As in all mammals, rat PGD was found to be controlled by an autosomal gene locus. The S phenotype seemed to be a consequence of a homozygous PGD genotype, PGDSPGDs. The SF and $F$ types, commonly found in wild but not laboratory rats, were considered to be the product of genotypes $P G D^{F} P G D S$ and $P G D F P G D^{F}$ respectively. Each (presumably allelic) gene was thought to code for one type of polypeptide subunit (either s or f) and the triplet zymogram in heterozygotes was considered to be the result of the random association in pairs of subunits of these two varicties, thus producing three dimeric oligomers: ss, sf and $\mathrm{ff}$. The threo types of rat $\mathrm{PGD}$ were not found to differ from each other with respect to optimal $p \mathrm{H}, K_{M}$ and stability.

There is some uncertainty about when Rattus norvegicus, the species prevalent in England and Europe at present, arose, and how and when it ousted the formerly universal Rattus rattus ${ }^{3}$. About $1728-1730$ has been quoted as the time of arrival of Rattus norvegicus in Britain. Although this species has been multiplying and evolving in the wild, many tame strains have been reared. But again, there is a lack of exact data as to origin. Thus the Wistar strain, one of the largest and most diversified of laboratory strains, was described by Castle ${ }^{4}$ merely as "of European origin". The strains reared in captivity have clearly been subjected to very different environmental stresses from their wild countcrparts, and they have different physiological and temperamental character istics ${ }^{3}$. In many cases the genetic make-up has been found to deviate from that of wild animals.

Table 1. FREQUExCY OH PGD PHENOTYPES AND ALLEIJS N WID RATS
Area

(1) Preston, Lancashire (2) Welsh borders (near
Shrewsbury)

(3) Birmingham

(4) Nottingham

(5) Cowbridge, Glamorgan

(6) Pontypool, Glamorgan

(7) Laleston, Calamorgan

(8) Usk, Monmouthshire

(9) Hersham, Surrey

(10) Slimfold, Surrey

(11) Cranleigh, Surrey

Totals

$\begin{array}{rrr}\text { No. observed } \\ \mathrm{l} & \mathrm{SF} & \mathrm{S} \\ 25 & 19 & 2 \\ 45 & 3 & 1 \\ & & \\ 29 & 5 & 2 \\ 56 & 6 & 1 \\ 35 & - & - \\ 40 & 14 & - \\ 37 & 7 & - \\ 7 & - & - \\ 11 & - & - \\ 40 & 2 & - \\ 22 & - & - \\ 327 & 56 & 6\end{array}$

\begin{tabular}{rcc}
\multicolumn{3}{c}{ No. predicted } \\
F & SF & S \\
$25 \cdot 9$ & $17 \cdot 3$ & $2 \cdot 9$ \\
$44 \cdot 1$ & $4 \cdot 7$ & $0 \cdot 1$ \\
& & \\
$27 \cdot 6$ & $7 \cdot 9$ & $0 \cdot 6$ \\
$55 \cdot 3$ & $7 \cdot 5$ & $0 \cdot 3$ \\
$35 \cdot 0$ & - & - \\
$40 \cdot 9$ & $12 \cdot 2$ & $0 \cdot 9$ \\
$17 \cdot 5$ & $6 \cdot 0$ & $0 \cdot 5$ \\
$7 \cdot 0$ & - & - \\
$11 \cdot 0$ & - & - \\
$40 \cdot 0$ & $2 \cdot 0$ & - \\
$22 \cdot 0$ & - & - \\
$326 \cdot 3$ & $57 \cdot 6$ & $5 \cdot 3$
\end{tabular}
of allele 0.25 0.05

$0 \cdot 12$

0.06

0.00

0.13

0.00

0.00

0.02

$0 \cdot 00$
Rats were trapped from various areas in England and Wales (Table 1), and we subjected blood haemolysates to starch gel electrophoresis, at $p \mathrm{H} 6.8$ in a gel containing phosphate buffer and stained histochemically for PGD, as described beforet. Some of the samples were also electrophoresed and stained histochemically for glucose 6-phosphate dehydrogenase, phosphoglucomutase, phosphoglucose isomerase, acid phosphatase, adenylate kinaso and lactate dehydrogenase, using established methods", but no variation was observed.

The three PGD phenotypes observed are shown in Fig. 1. The incidence of these three types in the wild rats examined is given in Table $\mathrm{I}$, along with the frequencies of the two alleles $P G D S$ and $P G D^{F}$, and also the predicted frequencies of the heterozygotes and homozygotes, in a population with this frequency of the two alleles, as calculated using

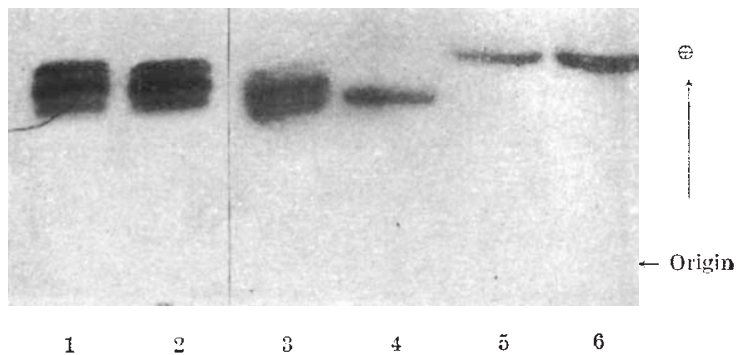

Fig. 1. Rat red cell electrophoretic phenotypes. Slots $1-3$, type SF; slot 4 , type $\mathrm{S}$; slots 5 and 6 , type $\mathrm{F}$.

the Hardy-Weinberg formulation ${ }^{6}$ (based on the assumption of random mating).

Laboratory rats from ten diverse strains were also tested, and only the single slow $\mathrm{S}$ phenotype was observed, indicating the absence of the $P G D^{F}$ allele. This finding contrasted sharply with the considerable incidence of this allele in wild rats from all the regions tested. We do not know whether this indicates some evolutionary change that occurrod in the wild or laboratory rat populations, during the 50-100 years ${ }^{4}$ thought to have elapsed since the strains separated, or whether it is the consequence of the fortuitous selection of rats of $S$ phenotype when the laboratory strains werc established.

It is worth noting that an analogous, although less extreme, situation occurs in humans, where the $P G D^{A}$ allele predominates but $P G D C$ oceurs as well in varying degrees ${ }^{1}$. There seems to be no method yet for ascertaining whether one or the other of those alleles is decreasing in frequency.

Studies of wild Rattus norvegicus from other parts of the world would be valuable. (Four such samples, originating in Austin, Texas, have been examined in this laboratory and found to be of $\mathrm{F}$ phenotype.)

We thank the staff of the Infestation Control Laboratories and the regional staff of the Ministry of Agriculture, Fisheries and Food for collecting rats. This work was supported by a grant to N. D. C. from the Royal Society.

\section{N. D. Carter}

C. W. PARR

Department of Biochemistry,

London Hospital Medical College,

Turner Street, London E1.

Received Scptcmber 15; revised October 6, 1969.

${ }^{1}$ Carter, N. D., Fildes, R. A., Fitch, L. 1., and Parr, C. W., Acta Genet., 18, $109(1968)$.

Carter, N. D., thesis, Univ. London (1967); Parr, C. W., Nature, 210, 487 $(1966)$.

${ }^{3}$ Robinson, R., Genetics of the Nortaly Rat (Pergamon Press, Tondon, 1965). 4 Castle, W. E., Troc. OS Nat. Acal. Sci., 33, 109 (1947).

5 Giblett, E. R., Genetic Markers in Human Blood (Blackwell, London. 1969).

'Hardy, G. H., Science, 28, 49 (1908); Weinberg, W., Jh. Ver. Vaterl. Naturk. Wurttemb., 64, 369 (1908).

\section{Is Tay-Sachs Disease Increasing?}

TAY-SACHS disease, caused by a recessive autosomal gene, occurs approximately a hundred times moro froquently in Jews from Central Europe (Ashkenazi) than in those from the Mediterranean Basin (Sephardic). Myrianthopoulos and Aronson ${ }^{1}$ proposed that the difference in gene frequency of the two populations is a consequence of simple heterozygote advantage in the Ashkenazi. Furthermore, they stated that this advantage probably arose fifty generations ago when there was a mass exodus of Jews after the Roman conquest of Jerusalem. The present gene frequencies in the two populations were given by Myrianthopoulos and Aronson as $q_{\mathrm{ASH}}=0.0126$ and $q_{\mathrm{SEPH}}=0.0013$. This corresponds to $q^{2} \mathrm{ASH}=0.000158$ and $q^{2} \mathrm{SEPH}=0.0000017$ or approximately 158 Tay-Sachs births per million among the 